Supporting Information for

\title{
Regulating the Catalytic Performance of a Dual-Atom Iron Species Deposited on Graphitic Carbon Nitride for Electrochemical Nitrogen Reduction
}

\author{
Bingxue Wang, Shan Huang, Lisheng Yang, Qiang Fu, ${ }^{\dagger+*}$ and Yuxiang Bu \\ School of Chemistry and Chemical Engineering, Shandong University, Jinan 250100, China \\ *Email: qfu3@ustc.edu.cn
}

Present Address:

${ }^{\dagger}$ Hefei National Laboratory for Physical Sciences at the Microscale, University of Science and Technology of China, Hefei 230026, China 


\section{1. $\mathrm{Fe}_{2} / \mathrm{g}-\mathrm{C}_{3} \mathrm{~N}_{4}$ configurations by using $2 \times 2$ and $3 \times 3$ supercells}

(a)

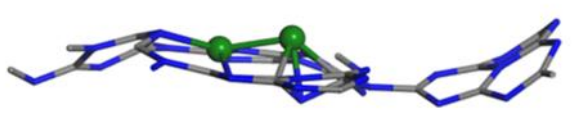

(c)

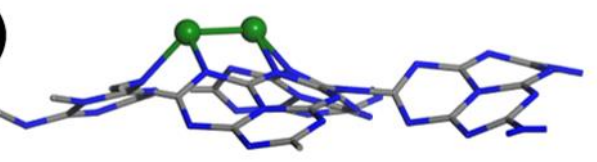

(b)

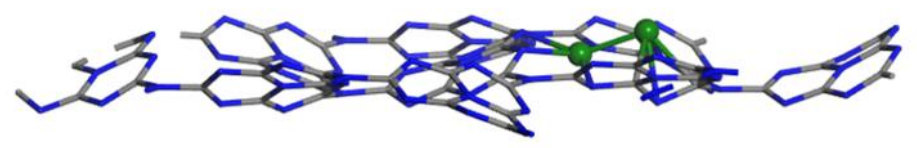

(d)

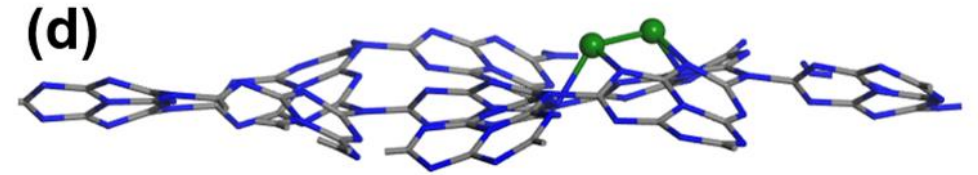

Figure S1. A side view of the optimized $\mathrm{Fe}_{2} / \mathrm{g}-\mathrm{C}_{3} \mathrm{~N}_{4}$ geometries. (a) and (b) display the asymmetric iron dimer by using the $2 \times 2$ and $3 \times 3$ supercells, respectively, and (c) and (d) show the corresponding nearly symmetric $\mathrm{Fe}_{2}$ species located on one side of the $g-\mathrm{C}_{3} \mathrm{~N}_{4}$ plane. The gray, blue, and green colors represent the $\mathrm{C}, \mathrm{N}$ and $\mathrm{Fe}$ atoms, respectively. 
Table S1. The energies and the magnetic moments of the $\mathrm{Fe}_{2} / \mathrm{g}-\mathrm{C}_{3} \mathrm{~N}_{4}$ structure obtained by using the $2 \times 2$ and $3 \times 3$ supercell. $\triangle \mathrm{E}$ is the energy difference between the two isomers using the same supercell.

\begin{tabular}{ccc|cc|c}
\hline & & \multicolumn{3}{c|}{} \\
\hline & $\begin{array}{c}\text { Energy } \\
(\mathrm{eV})\end{array}$ & $\begin{array}{c}\text { Magnetic } \\
\text { moment }\end{array}$ & $\begin{array}{c}\text { Energy } \\
(\mathrm{eV})\end{array}$ & $\begin{array}{c}\text { Magnetic } \\
\text { moment }\end{array}$ & $\triangle \mathrm{E}(\mathrm{eV})$ \\
\hline $\begin{array}{c}2 \times 2 \\
\text { supercell }\end{array}$ & -390.62 & 4.0010 & -390.60 & 6.1294 & -0.02 \\
\hline $\begin{array}{c}3 \times 3 \\
\text { supercell }\end{array}$ & -876.35 & 4.0002 & -875.62 & 6.0000 & -0.73 \\
\hline
\end{tabular}

Table S2. The calculated $\mathrm{N}_{2}$ adsorption energies on $\mathrm{Fe}_{2} / \mathrm{g}-\mathrm{C}_{3} \mathrm{~N}_{4}$ by using the $2 \times 2$ and $3 \times 3$ supercells.

\section{$2 \times 2$ supercell $3 \times 3$ supercell}

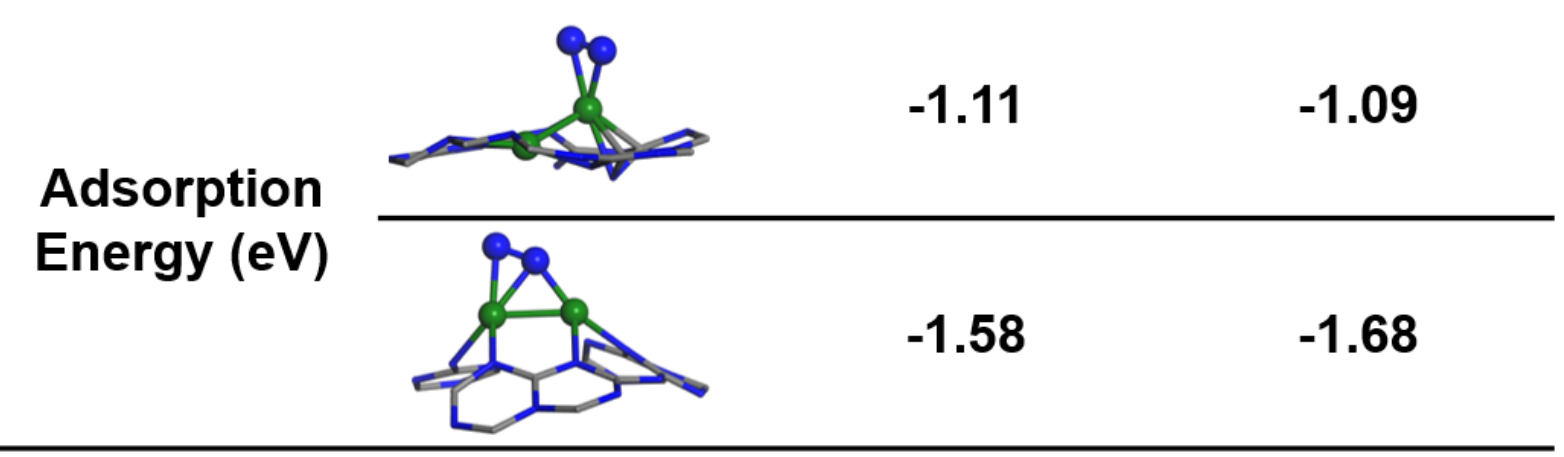




\section{Spin-resolved density distribution of the $\mathrm{Fe}_{2} / \mathrm{g}-\mathrm{C}_{3} \mathrm{~N}_{4}$ system}
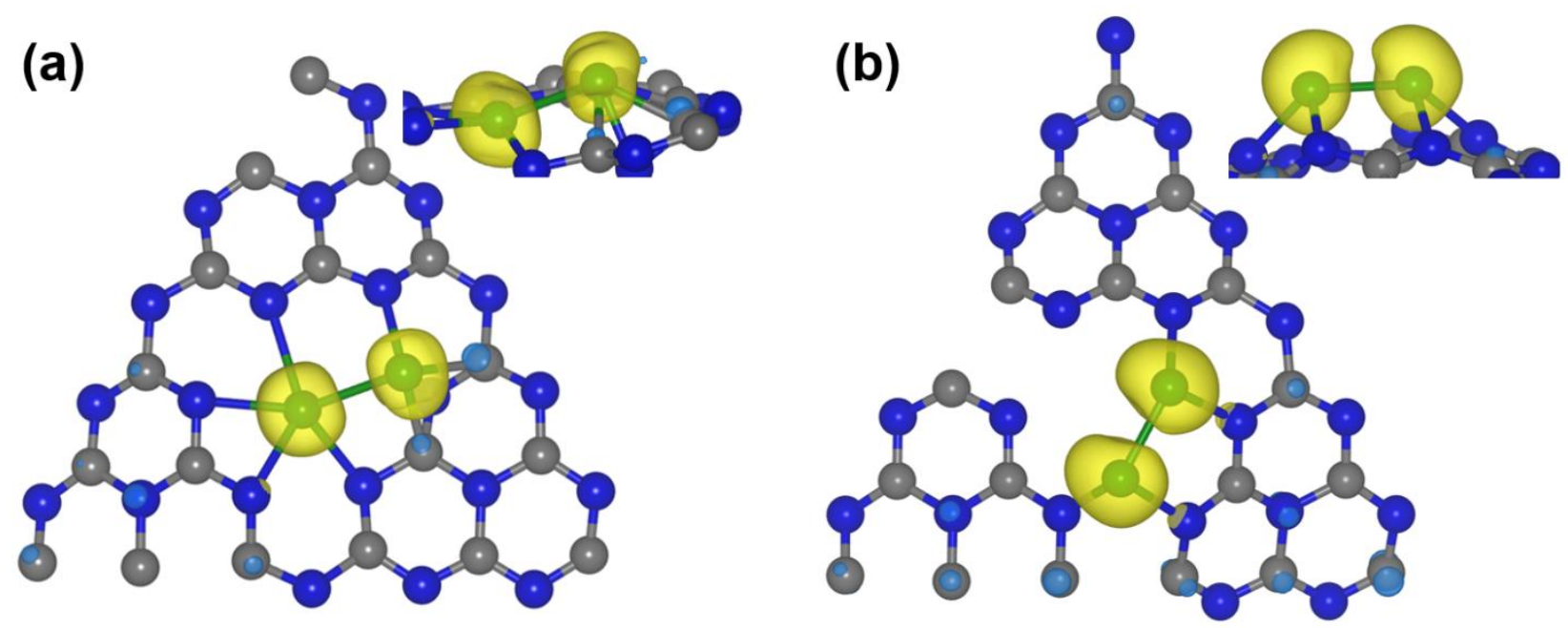

Figure S2: Spin-resolved density distribution of the $\mathrm{Fe}_{2} / \mathrm{g}-\mathrm{C}_{3} \mathrm{~N}_{4}$ system with the iron dimer located within (a) or on one side of the $\mathrm{g}-\mathrm{C}_{3} \mathrm{~N}_{4}$ monolayer (b). The yellow and blue colors correspond to the two different spin orientations. 


\section{Free energy profiles of the other seven NRR pathways}

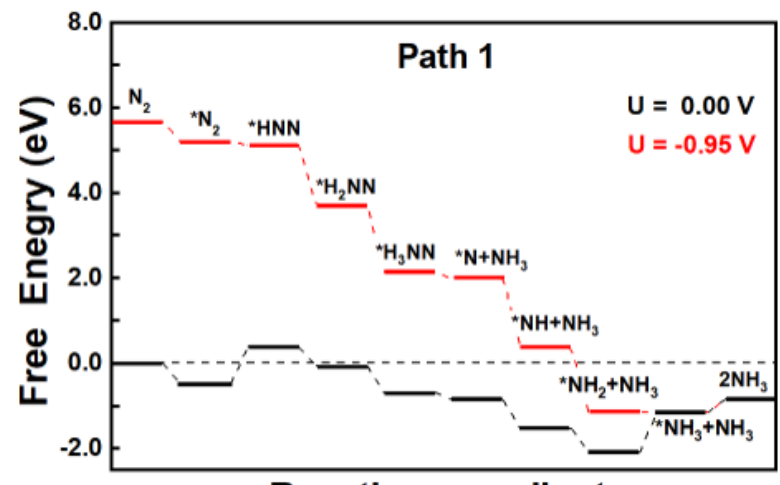

Reaction coordinate

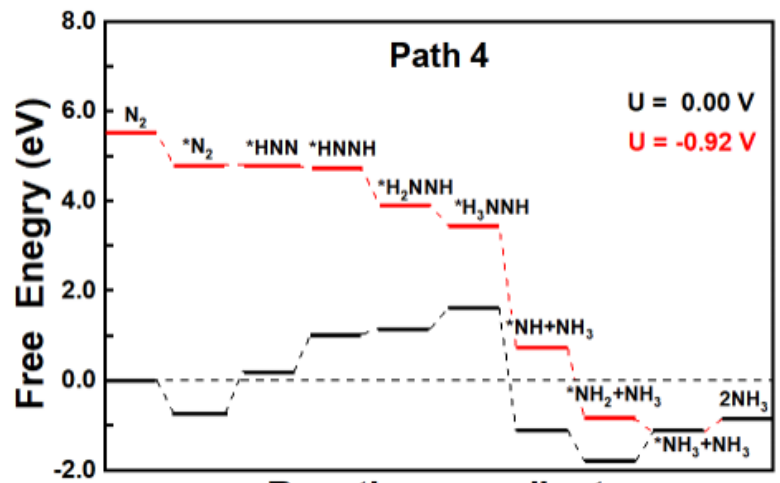

Reaction coordinate

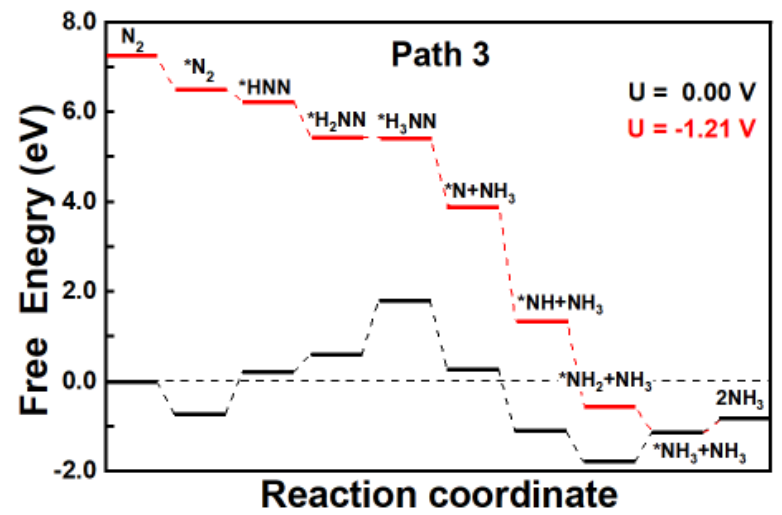

Figure S3: Free energy diagrams of the NRR pathways (Paths 1, 3, and 4) on the $\mathrm{Fe}_{2} / \mathrm{g}-\mathrm{C}_{3} \mathrm{~N}_{4}$ electrocatalyst without applying the strain. Here, the iron dimer adopts an asymmetric geometry and is located within the g- $\mathrm{C}_{3} \mathrm{~N}_{4}$ plane. The free energy diagram of the Path 2 is shown in the main text as Figure 5. The numbering of the pathways is consistent with that in the Table 1. 


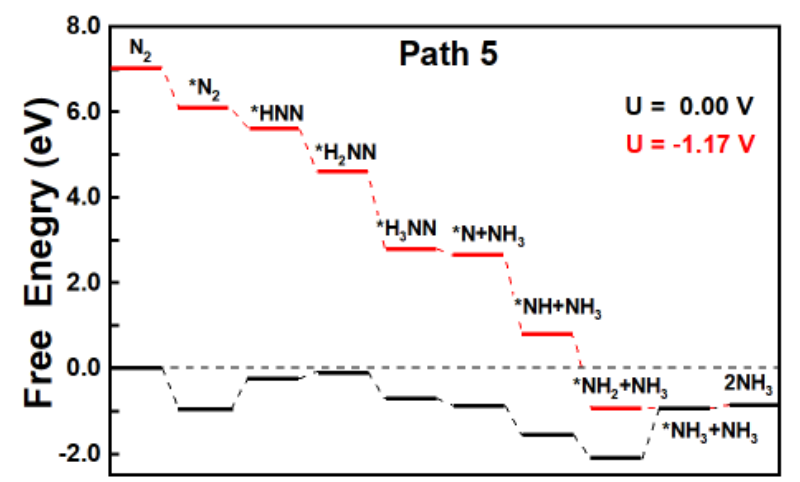

Reaction coordinate

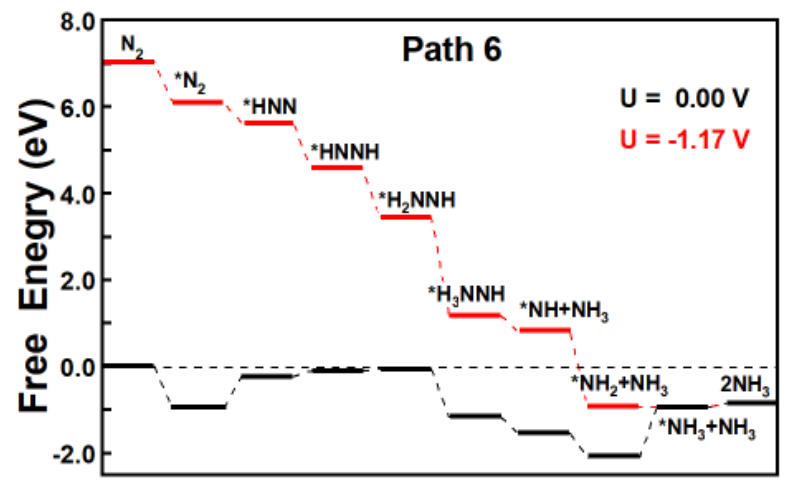

Reaction coordinate
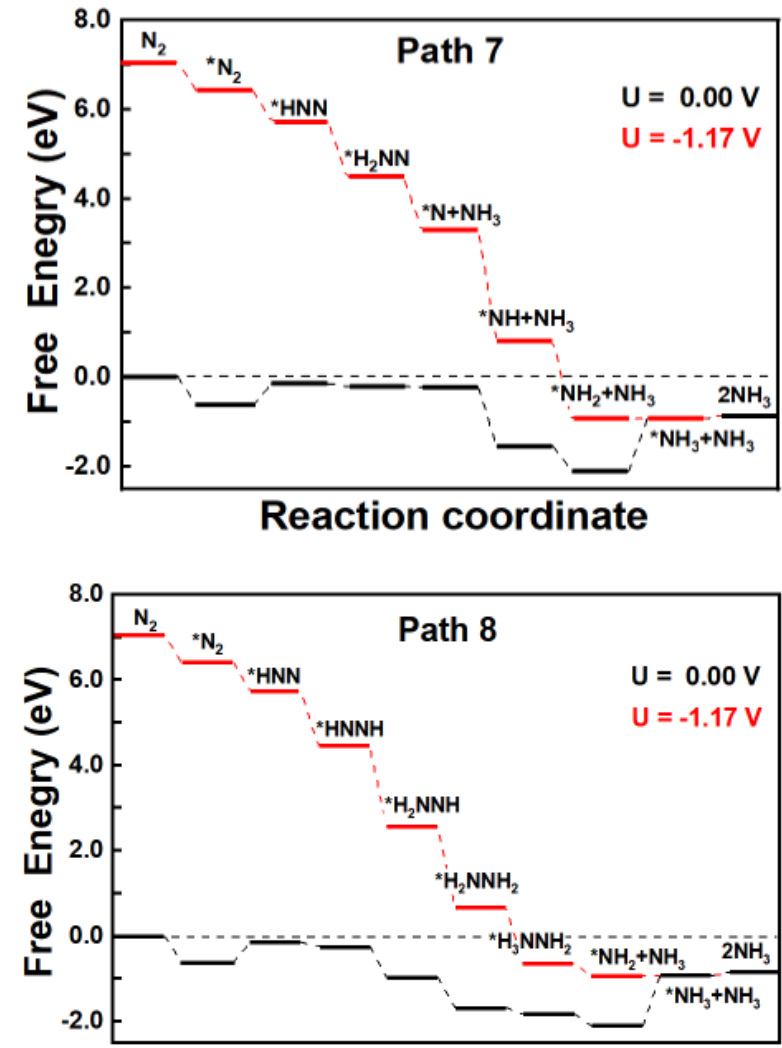

Reaction coordinate

Figure S4: Free energy diagrams of the NRR pathways (Paths $5-8$ ) on the $\mathrm{Fe}_{2} / \mathrm{g}-\mathrm{C}_{3} \mathrm{~N}_{4}$ electrocatalyst without applying the strain. Here, the iron dimer adopts a nearly symmetric geometry and is located on one side of the g- $\mathrm{C}_{3} \mathrm{~N}_{4}$ plane. The numbering of the pathways is consistent with that in the Table 1. 


\section{Trajectory from the $\boldsymbol{A b}$ initio molecular dynamics (AIMD)}

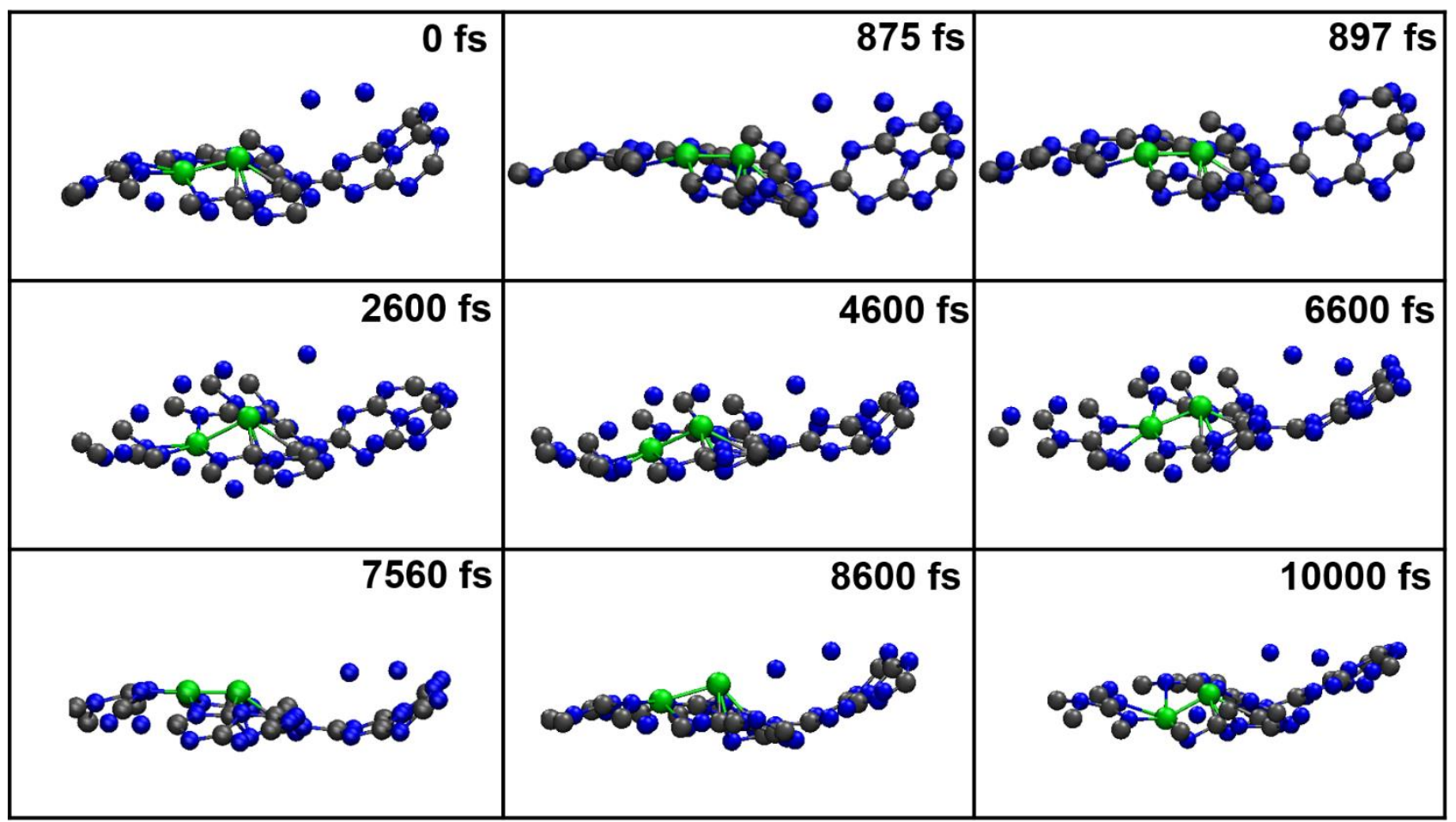

Figure S5. Selected snapshots of the AIMD trajectory for the $\mathrm{Fe}_{2} / \mathrm{g}-\mathrm{C}_{3} \mathrm{~N}_{4}$ system. Here, at $897 \mathrm{fs}$ and $7560 \mathrm{fs}$, the iron dimer is the nearly symmetric $\mathrm{Fe}_{2}$ species located on one side of $\mathrm{g}-\mathrm{C}_{3} \mathrm{~N}_{4}$ plane. The gray, blue, and green spheres represent the $\mathrm{C}, \mathrm{N}$ and $\mathrm{Fe}$ atoms, respectively. 
5. Results from the (AIMD) simulations of the $\mathrm{Fe}_{2} / \mathrm{g}-\mathrm{C}_{3} \mathrm{~N}_{4}$ system upon the application of $2 \%$ tensile strain

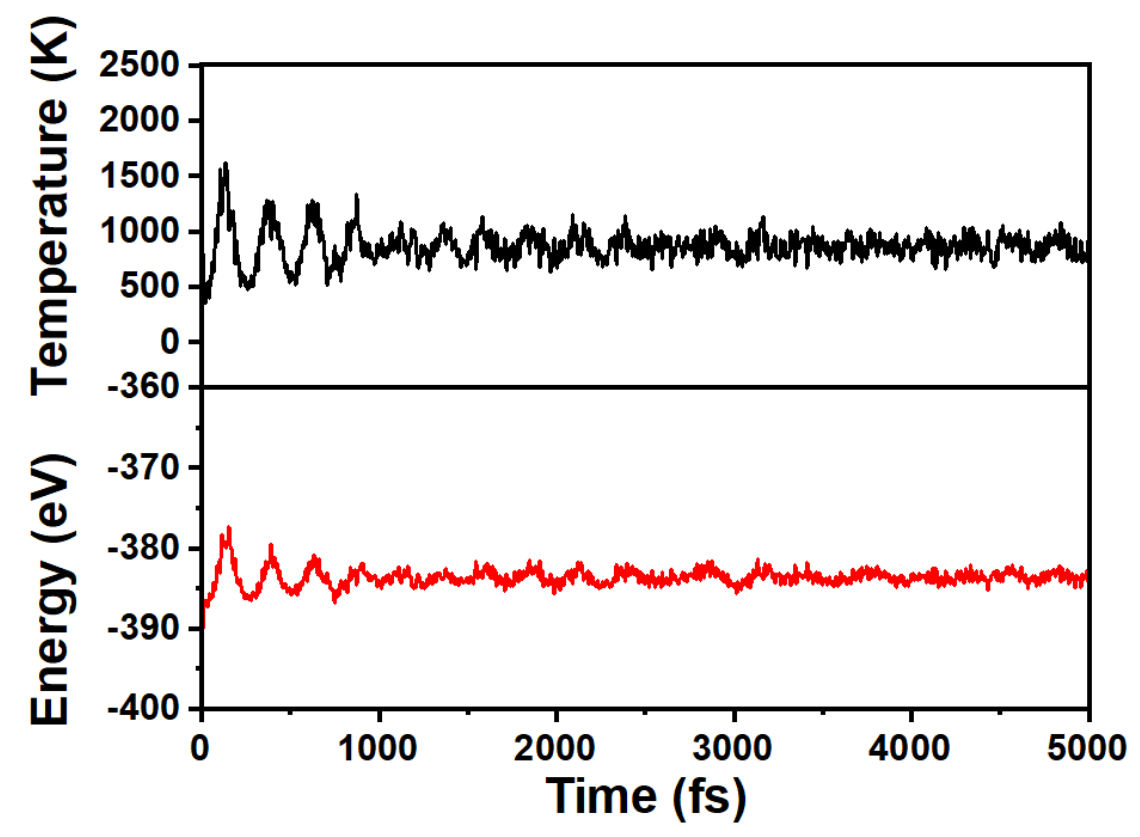

Figure S6: Temperature variation and energy fluctuations from the AIMD simulations for the $\mathrm{Fe}_{2} / \mathrm{g}-\mathrm{C}_{3} \mathrm{~N}_{4}$ system under $2 \%$ tensile strain. 


\section{Free energy profiles of the eight NRR pathways upon the application}

\section{of the $2 \%$ tensile strain}
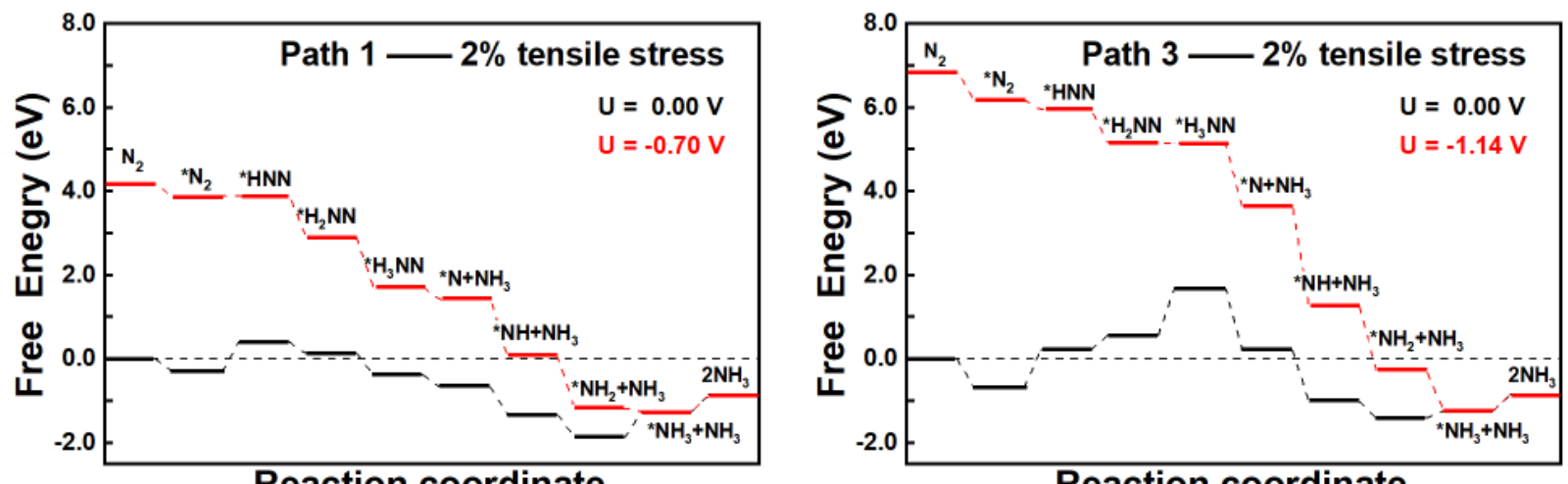

Reaction coordinate

Reaction coordinate
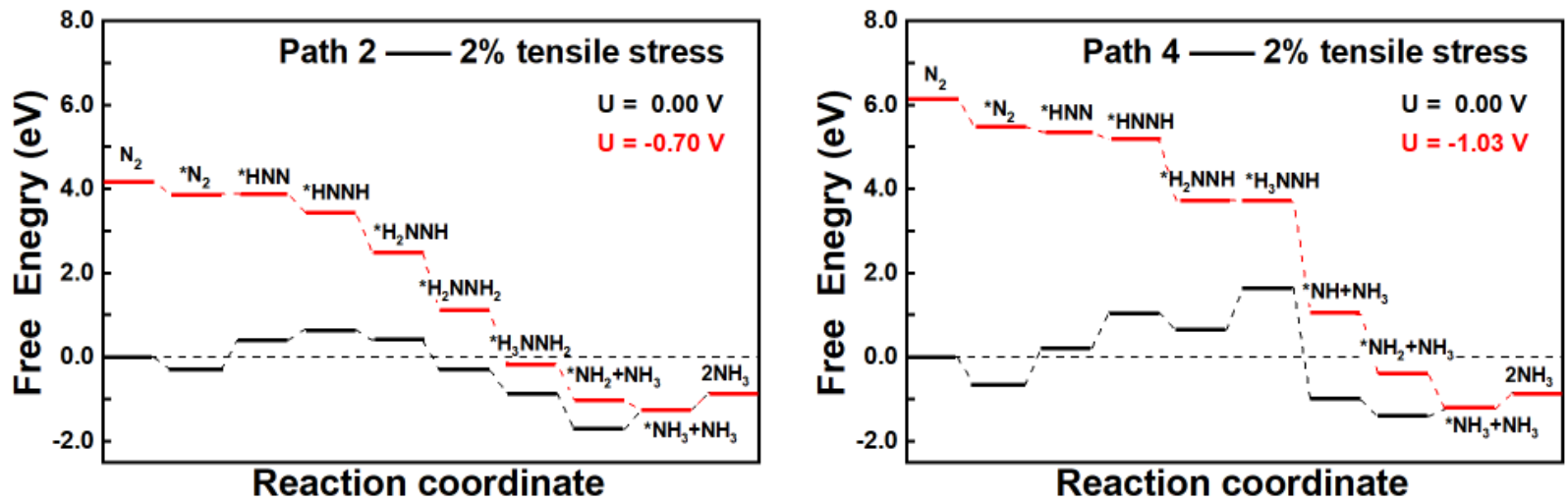

Figure S7: Free energy profiles of the four NRR pathways (Paths $1-4$ ) upon a $2 \%$ tensile strain is applied. Here, the iron dimer adopts an asymmetric geometry and is located within the g- $\mathrm{C}_{3} \mathrm{~N}_{4}$ plane. The numbering of the pathways is consistent with that in Table 1 . 

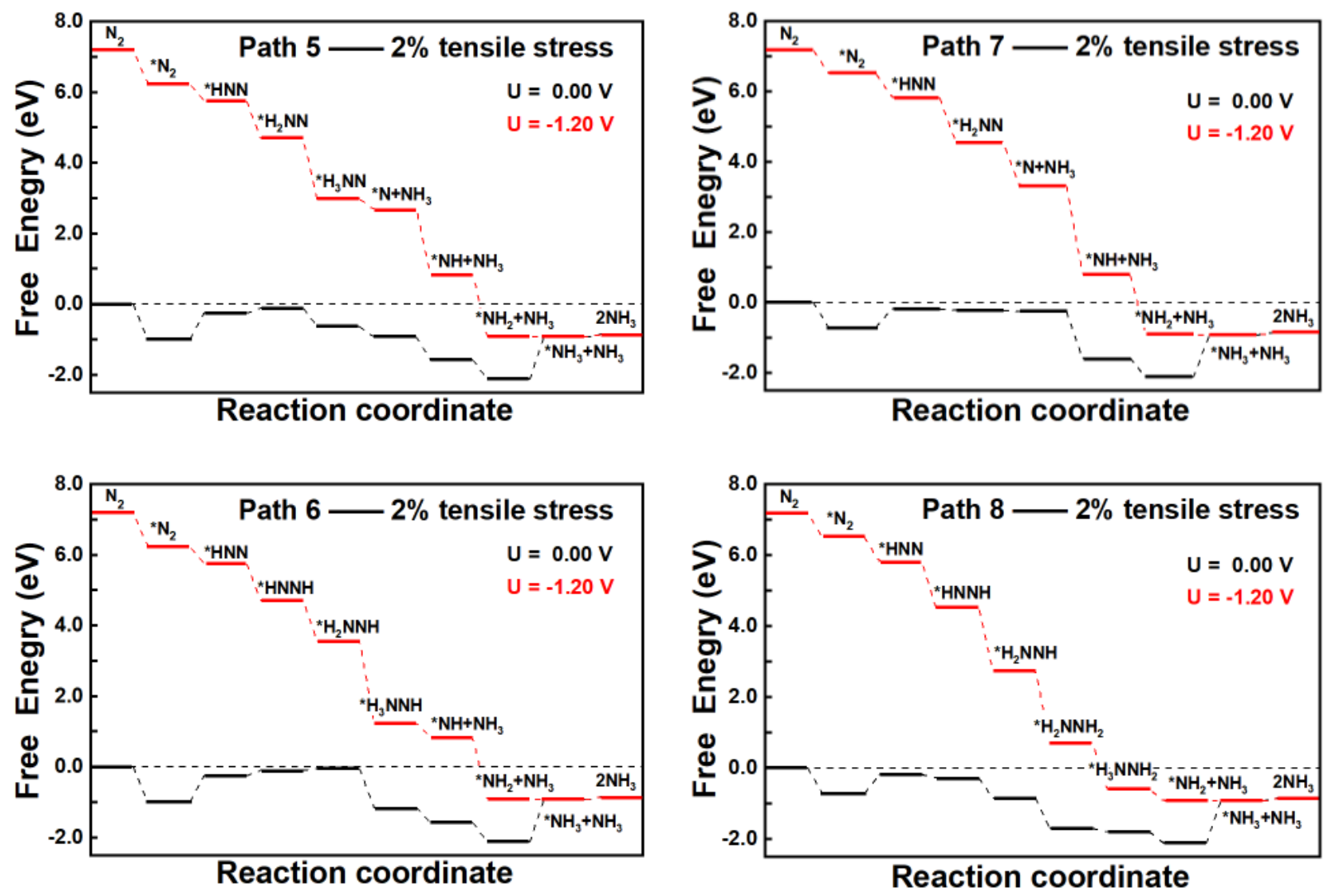

Figure S8: Free energy profiles of the four NRR pathways (Paths $5-8$ ) upon a $2 \%$ tensile strain is applied. Here, the iron dimer adopts a nearly symmetric geometry and is located on one side of the g- $\mathrm{C}_{3} \mathrm{~N}_{4}$ plane. The numbering of the pathways is consistent with that in Table 1. 


\section{Calculated Fe-N bond length variations under external strains}

When we explored the role of the geometric effects played in the change of the NRR overpotential value that is induced by the external strains, we have considered a variety of factors, including the three Fe-N bonds formed by the Fe atom and the other three $\mathrm{N}$ atoms (shown in Figures S9b-d), except for the particular Fe-N bond mentioned in the main text (also shown in Figure S9a). We found that only the length change of that Fe-N bond (Figure S9a) matches well with the change in the adsorption energies of ${ }^{*} \mathrm{~N}_{2}$ and ${ }^{*} \mathrm{HNN}$. Besides, only the bond length of that $\mathrm{Fe}-\mathrm{N}$ bond exhibits a relatively large change with the application of the external strains, which is at least $0.17 \AA$. The length changes of the other three Fe-N bonds, by contrast, are relatively small and in most cases not higher than $0.07 \AA$ (except the length change shown by the red line in Figure S9c that reaches 0.12 $\AA)$. Therefore, at least qualitatively, we believe that the length change in the particular Fe-N bond is responsible for the breaking of the scaling relations that finally leads to the reduction of the NRR overpotential value.
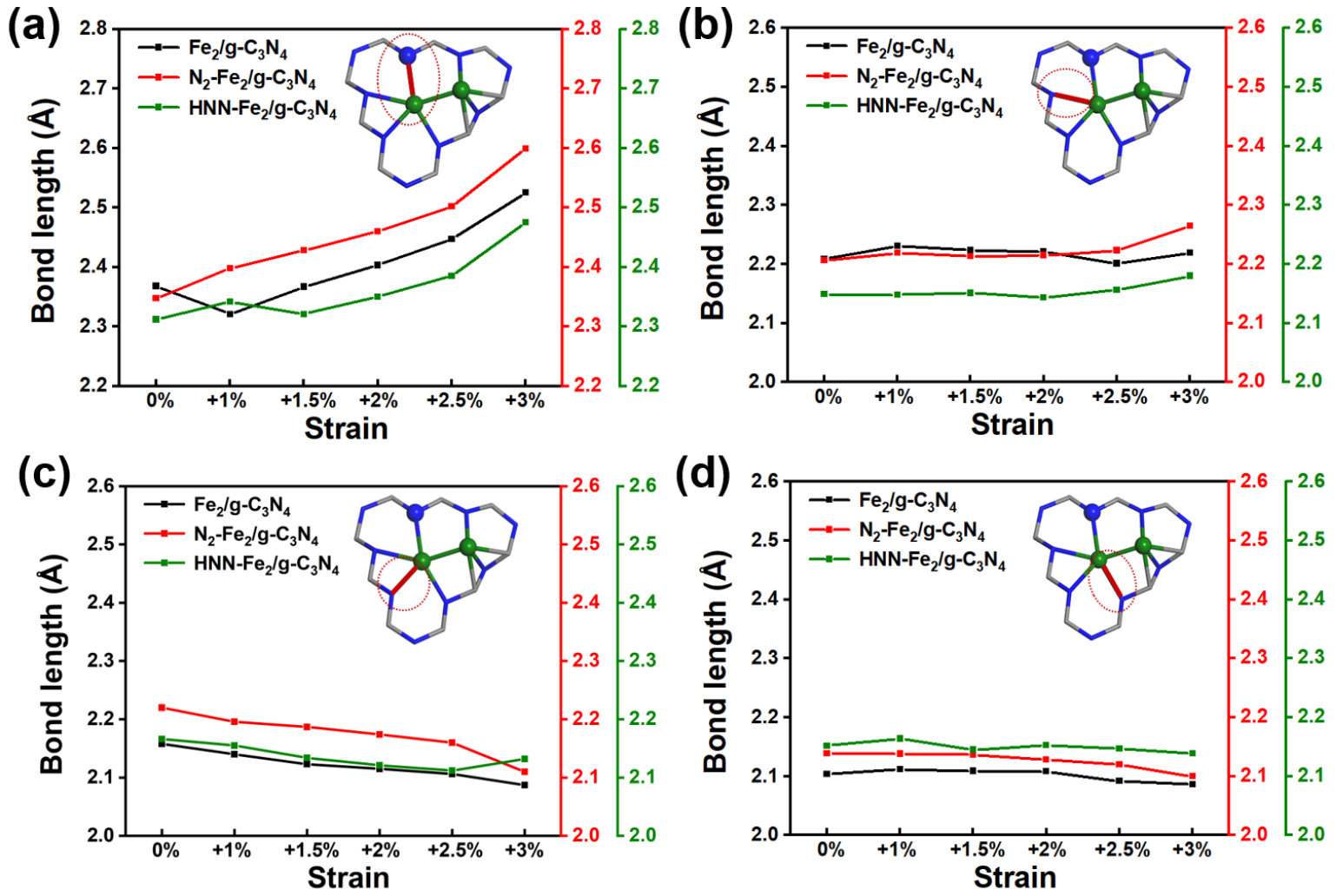

Figure S9: The Fe-N bond lengths of the $\mathrm{Fe}_{2} / \mathrm{g}-\mathrm{C}_{3} \mathrm{~N}_{4}$ system itself (black line) as well as those upon $* \mathrm{~N}_{2}$ (red line) or ${ }^{*} \mathrm{HNN}$ (green line) adsorption under different external strains. The Figure S9a is the same as the Figure 8a shown in the main text, for the sake of comparison. 


\section{Configurations of $\mathrm{Fe}_{2} / \mathrm{g}-\mathrm{C}_{3} \mathrm{~N}_{4}$ after heteroatom doping}

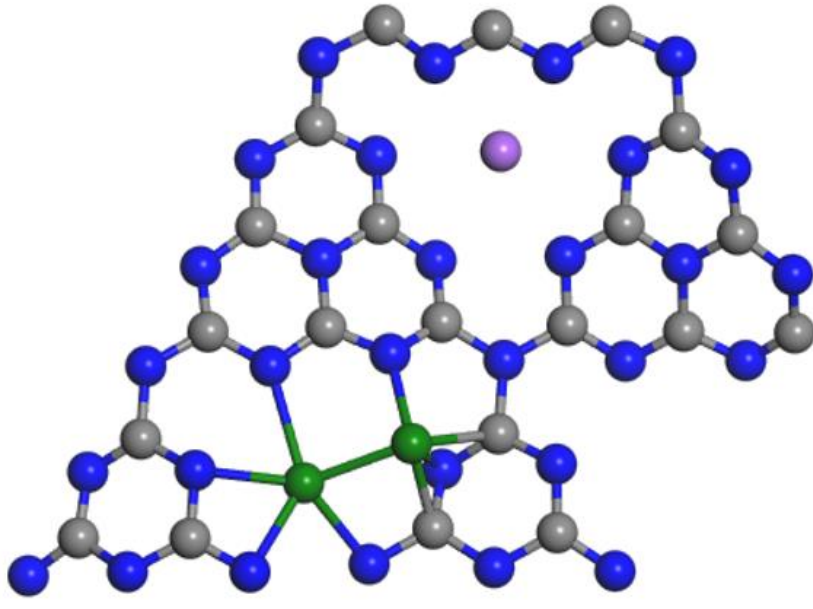

(a)

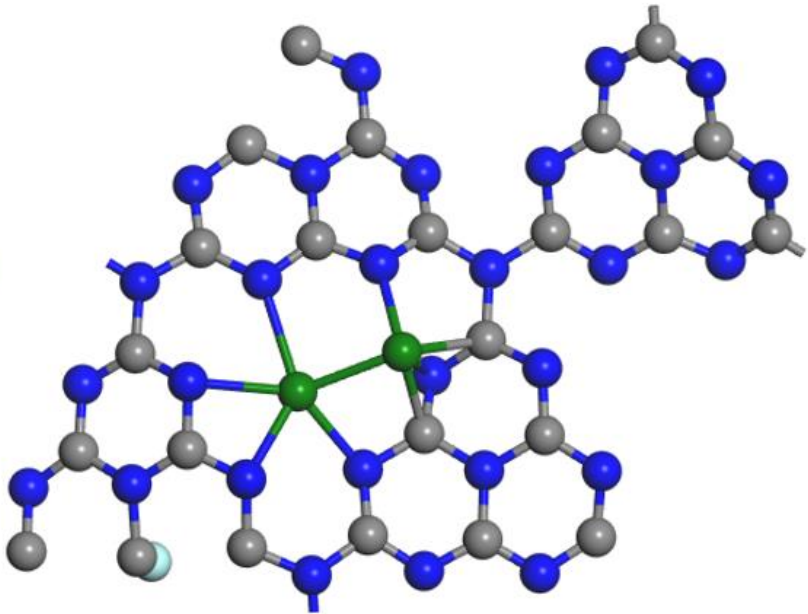

(b)

Figure S10: Configurations of the $\mathrm{Fe}_{2} / \mathrm{g}-\mathrm{C}_{3} \mathrm{~N}_{4}$ electrocatalyst after doping a sodium (a) or a fluorine (b) atom. The purple and cyan spheres represent the $\mathrm{Na}$ and $\mathrm{F}$ atoms, respectively. The iron dimer adopts an asymmetric geometry and is located within the $\mathrm{g}-\mathrm{C}_{3} \mathrm{~N}_{4}$ plane. 
9. Results from the (AIMD) simulations of the $\mathrm{Fe}_{2} / \mathrm{g}-\mathrm{C}_{3} \mathrm{~N}_{4}$ system upon Na atom doping

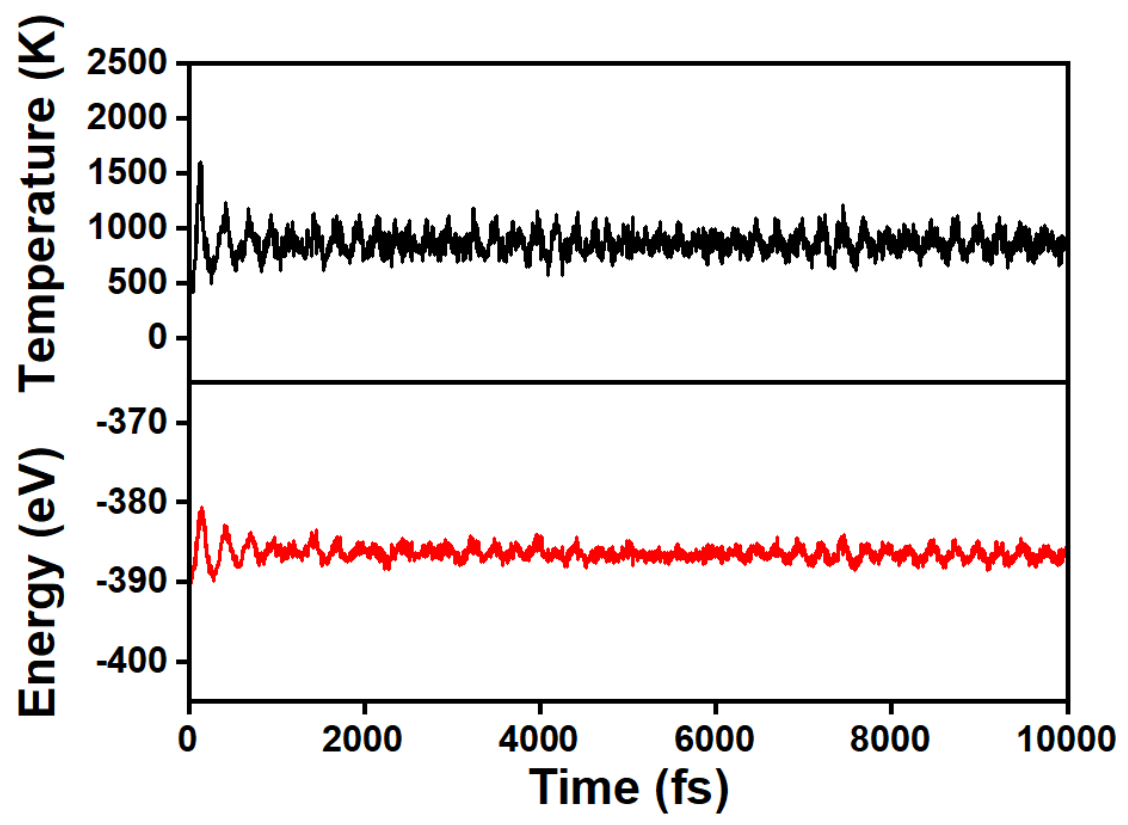

Figure S11: Temperature variation and energy fluctuations from the AIMD simulations for the $\mathrm{Fe}_{2} / \mathrm{g}-\mathrm{C}_{3} \mathrm{~N}_{4}$ system upon $\mathrm{Na}$ atom doping. 